Chapter 9

\title{
Non-Catalytic Production of Ethyl Esters Using Supercritical Ethanol in Continuous Mode
}

\author{
Camila da Silva, Ignácio Vieitez, Ivan Jachmanián, \\ Fernanda de Castilhos, Lúcio Cardozo Filho and \\ José Vladimir de Oliveira \\ Additional information is available at the end of the chapter \\ http://dx.doi.org/10.5772/52013
}

\section{Introduction}

Development of alternative renewable energy has become necessary because, among other factors, the possible shortage of fossil fuels and environmental problems. Among the renewable resources available for alternative fuel production, the conversion of fats and oils to biodiesel has been investigated and well documented in the literature [1-4].

The merits of biodiesel as an alternative to mineral diesel comprise a nontoxic, biodegradable, domestically produced, and renewable resource. Besides, biodiesel possesses a higher cetane number compared to diesel from petroleum and a favorable combustion emissions profile, such as reduced levels of particulate matter, carbon monoxide, and, under some conditions, nitrogen oxides [5,6]. Because of these environmental benefits, which means reduction of environmental investments, and also due to the relief from reliance on import needs, biodiesel fuel can be expected to become a good alternative to petroleum-based fuel.

The establishment of the Brazilian national program on biodiesel has prompted several studies on biodiesel production using different techniques and a variety of vegetable and animal sources. Methanol has been the most commonly used alcohol to perform transesterification reactions. However, in the Brazilian context, ethanol has been the natural choice since Brazil is one of the world's biggest ethanol producers, with a well-established technology of production and large industrial plant capacity installed throughout the country. Due to the fact that ethanol also comes from a renewable resource, thus, ethanol biodiesel appears as a $100 \%$ renewable alternative additionally enabling the replacement of traditionally used methanol by an innocuous reagent [7]. 
Typical raw materials investigated for the production of biodiesel, include soybean, sunflower, castor, corn, canola, cottonseed, palm, peanuts [1] and more recent studies highlight the use of Jatropha curcas oil [8,9]. A fact to be also considered to lower manufacturing costs and make biodiesel competitive, is the use of degummed oils that have lower cost than refined oils, besides the possibility of recycling the waste oils $[10,11]$. However, the choice of the oilseed to be used must consider the content in vegetable oil, yield and territorial adaptation.

Among other processes used for the production of biofuels from vegetable oils, such as pyrolysis and microemulsification, transesterification is the most common way to produce biodiesel $[1,3]$. Transesterification, also called alcoholysis, refers to the reaction of a triglyceride (from animal or vegetable source) with an alcohol in the presence or absence of catalyst to form fatty acid alkyl esters (i.e., biodiesel) and glycerol as a byproduct.

The complete transesterification is the reaction of one mole of triglyceride with three moles of alcohol, resulting in the production of 3 moles of esters and $1 \mathrm{~mol}$ of glycerol as shown in Figure 1. Transesterification is a reversible reaction which occurs in three steps with formation of intermediate products: diglycerides and monoglycerides.<smiles>[R]C1=CC(=O)OCC2COC(=O)OCC(C1)O2</smiles>

Triglyceride<smiles>O[R][Te]</smiles>

Alcohol

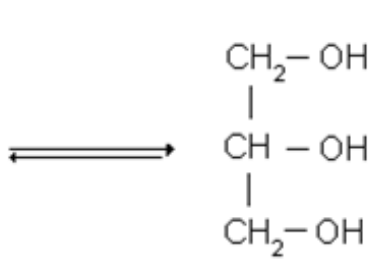

Glycerol<smiles></smiles>

Esters

Figure 1. Transesterification reaction of a triglyceride with an alcohol.

The transesterification process reduces the average molar mass to approximately $1 / 3$ compared to triglycerides, hence decreasing the viscosity and enhancing the mixture volatility. Unlike the original oil, biodiesel has similar properties and full compatibility with petroleum diesel, accordingly conventional diesel engines can be powered on biodiesel without requiring substantial mechanical modification [12]. After the reaction, the products consist of a mixture of fatty acid esters, glycerol, remainder alcohol, catalyst and a low percentage of tri-, di-and monoglycerides [13].

Among the factors affecting the yield of the transesterification reaction, one can cite: type and amount of catalyst, reaction time, temperature, molar ratio of oil to alcohol, content of free fatty acids and water in the substrates, agitation power, solubility between the phases and nature of the alcohol [10]. However, the extent of variables effect will necessarily depend on the method used [14]. 
The homogeneous chemical catalysis (acid or basic) is the most used technique in the transesterification reaction at industrial scale, since it allows, in the case of alkaline catalysis, reaching high conversions at shorter reaction times [15-23].

The chemical method using homogeneous alkali catalysts, although simple, fast and with high yields, presents several drawbacks, such as costs of catalyst separation and difficulty of purification and separation of reaction products, which involves high production costs and energy consumption [24]. Because alkali catalyzed systems are very sensitive to both water and free fatty acids contents, the glycerides and alcohol must be substantially anhydrous. Water makes the reaction partially change to saponification, which produces soaps, thus consuming the catalyst and reducing the catalytic efficiency, as well as causing an increase in viscosity, formation of gels, and difficulty in separations $[1,3,25]$. As a consequence, the water and free fatty acids content should be less than $0.06 \%(\mathrm{w} / \mathrm{w})$ and $0.5 \%(\mathrm{w} / \mathrm{w})$ for transesterification reaction with alkali catalysts, respectively $[1,26]$.

The transesterification reaction using homogeneous acid catalysts is preferred for the conversion of raw materials containing high levels of free fatty acids, because the acid catalyst can promote simultaneously the transesterification of the triglycerides and esterification of the free fatty acids to alkyl esters [27]. Although esterification of free fatty acids may proceed with a relatively high rate and high yields can be achieved, the kinetics of triglycerides transesterification is much slower, requiring high temperatures (above $373 \mathrm{~K}$ ) and 24 hours of reaction for completion [12].

Thus obtaining of esters in two reaction steps for substrates with high acidity has been proposed, consisting of two approaches: (a) the acid esterification of free fatty acids and subsequent the alkaline transesterification of triglycerides [28-31] or (2) enzymatic hydrolysis of triglycerides, followed by the acid esterification of the fatty acids produced [32-34].

The use of heterogeneous chemical catalysts in alcoholysis of vegetable oils reduces the difficulties of separation of products and catalyst, resulting in the generation of lower effluents volume. The literature suggests the use of various acid and basic catalysts [35-37], with catalysts reuse in the process. However, heterogeneous chemical catalysis generally shows low yields compared to homogeneous alkaline catalysis.

The reaction catalyzed by enzymes (lipases) provides easy separation of catalyst from the reaction medium, catalyst reusability and higher purity of the reaction products. However, to date, the main disadvantages of this method refers to the long reaction times needed and the high cost of the enzymes [14], that progressively are deactivated during reaction course. The enzyme method can be conducted in the presence of organic solvents in order to minimize mass transfer limitations, immiscibility between phases and catalyst deactivation, requiring the use of higher ratios of solvent/vegetable oil (in the order of 40/1) to provide satisfactory reaction rates [38]. For the production of biodiesel in enzyme systems using pressurized solvents, smaller amounts of solvent can be used and the solvent can be easily separated from the reaction medium by system decompression [38-41]. High conversions have been reported for both systems but the use of high enzyme to substrates ratios has hindered large-scale implementation of such technique. 
The efficiency of microwave irradiation [42-44] and the use of ultrasonic technology [45-47] in the transesterification of vegetable oils using different catalysts has been reported with the advantage of high reaction rates compared to conventional processes.

Recently, a catalyst-free technique for the transesterification of vegetable oils using an alcohol at supercritical conditions has been proposed, keeping the benefits of fuel quality and taking into account environmental concerns [48-53]. According to the current literature, catalyst-free alcoholysis reactions at high temperature and pressure conditions provide improved phase solubility, decreased mass-transfer limitations, afford higher reaction rates and simpler separation and purification steps [24]. Besides, it has been shown that the socalled supercritical method is more tolerant to the presence of water [54] and free fatty acids $[54,55]$ than the conventional alkali-catalyzed technique, and hence more tolerant to various types of vegetable oils, even for fried and waste oils.

The reaction for biodiesel production at supercritical conditions requires high alcohol to oil molar ratios and the adoption of high temperatures and pressures for the reaction to present satisfactory conversion levels, leading to high processing costs and causing in many cases the degradation of the fatty acid esters formed [56-60] and reaction of glycerol formed with other components of the reaction medium [61-64], hence decreasing the reaction conversion $[65-68,57,58]$. Current literature shows some alternatives to reduce the expected high operating costs and product degradation, and such strategies usually involve: (i) addition of cosolvents [69-74]; (ii) two-step process with glycerol removal in the first step [75-77]; (iii) twostep process comprising hydrolysis of triglycerides in subcritical water and subsequent esterification of fatty acids $[65,66,78]$; (iv) use of microreator systems operating in continuous mode [74,79] and use of packed bed reactor [80].

The aim of this work is to provide a brief review on the continuous production of fatty acid ethyl esters (FAEE) by non-catalytic process using ethanol at supercritical conditions. These results are part of a broader project aimed at building a platform to allow the development of a new process for the production of biodiesel from vegetable oils. A section of this chapter will be dedicated to reviewing the characteristics of the supercritical method, comprising the research in the production of FAEE in continuous mode evaluating the role of process variables such as temperature, pressure, molar ratio of oil:ethanol and residence time. This review also focuses on the different configurations of reaction systems, like tubular reactor, microtube reactor, packed bed tubular reactor, as well as the experimental simulation of reactors in series and reactor with recycle. The effect of addition of co-solvent (carbon dioxide), water and free fatty acids to the reaction medium on the FAEE yield are evaluated and decomposition of FAEE produced and conversion of oil to FAEE are also considered.

\section{Characteristics of the non-catalytic supercritical method for biodiesel production}

The transesterification reaction using a solvent at pressurized conditions is one of the methods used for the synthesis of biodiesel [48]. This can be a secure way, without caus- 
ing environmental damage, and requires less investment in the overall process, since the equipment cost is offset by the high reaction rates, better efficiency and lower cost of products purification.

Glisic \& Skala [81] reported the economic analysis of the processes for biodiesel production using homogeneous alkaline catalysis and supercritical method, noting that energy consumption is extremely similar in both cases. Since in the supercritical method the heating step involves high energy consumption, costs are compensated by the simpler purification step of the products (esters and glycerol), requiring lower power consumption, which leads to a high costs step of the conventional process. Deshpande et al. [82] reported an economic analysis of the proposed supercritical process and found that the biodiesel processing cost through the proposed technology could be half of that of the actual conventional methods.

The production costs of biodiesel can be minimized by the sale of by-products generated by the transesterification process, such as glycerin. However, when using the conventional method by alkaline catalysis, traces of catalyst can be found in the glycerin, which limits the use of this product. Thus subsequent purification steps are required [83,84], a fact that is not needed in the supercritical method, which proceeds with simple purification and separation of the biofuel produced and generates a high-pure glycerin $[48,49,85]$.

Marchetti \& Errazu [85] evaluated different processes for biodiesel production using vegetable oils with high content of free fatty acids, including the supercritical method and stated that the supercritical method is an attractive alternative from a technological point of view. Additionally, from the economic point of view, less wastewater is produced and a high quality glycerin is generated as a byproduct, however higher energy is required by the reaction step.

The reactivity in the supercritical state is higher than in the liquid or gas, which facilitates the transesterification reaction [86]. The supercritical point of ethanol and methanol are 514 $\mathrm{K}$ and 6.14 Mpa [27,51] and 513 K and 8.09 Mpa [48], respectively. The non-catalytic production of biodiesel with supercritical alcohol provides high reaction yields, since it promotes the simultaneous hydrolysis and transesterification of triglycerides and esterification of free fatty acids present in vegetable oil [50].

The supercritical method has the following advantages over other methods used for biodiesel production [67]:

a. Catalyst is not used in the reaction and purification procedures are much simpler, since the separation process of the catalyst and the saponified product is not required;

b. The supercritical reaction requires shorter reaction time than the traditional catalytic transesterification and the conversion rate is high. The catalytic transesterification requires, in some cases, hours to reach the reaction equilibrium, while supercritical method only minutes;

c. Low quality substrates of can be used in the supercritical method, since high levels of free fatty acids and water do not have a negative effect on the reaction. 
The alcohol in the supercritical state solves or reduces the possible formation of two phases to form a single homogeneous phase, by decreasing the dielectric constant of alcohol in the supercritical state, which results in increased solubility of the oil [24]. Ma \& Hanna [1] reported that the solubility of triglycerides in methanol increases at a rate of 2 to $3 \%(\mathrm{w} / \mathrm{w})$ of $10 \mathrm{~K}$ increase in temperature.

Some disadvantages of supercritical method are nevertheless pointed out: high alcohol to oil ratios are required (in the order of 40:1), best results are obtained at temperatures above 573 $\mathrm{K}$ and high pressures, typically $20 \mathrm{MPa}$, which leads to high processing costs and energy consumption. In addition, the quality of biodiesel may be compromised by the low stability of certain fatty acid esters exposed to the drastic reaction conditions required. Thus, due to drastic increase in costs associated with the use of excess alcohol and equipment due to operation at high temperatures and pressures, improvements to the supercritical method for producing biodiesel are required [87].

Kiwjaroun et al. [88] investigated the biodiesel production processes by supercritical methanol combined with and alkaline catalyst and the impacts generated by each process on the environment, using LCA (life cycle analysis) as a tool. It was observed by these researchers that the supercritical method is advantageous compared to conventional method due to the less amount of wastewater generated, however, creates a high impact on the environment, mainly due to the large amount of alcohol used in the process, emphasizing the need for research regarding the reduction in operating conditions (temperature, pressure) and the amount of alcohol used in the process. Marulanda [89] evaluated the potential environmental impact assessment of the process for biodiesel production by non-catalyst supercritical method and conventional base-catalyzed process. The environmental assessment results indicated the supercritical process, even when working at a 42:1 molar ratio, has a lower impact than the conventional base-catalyzed process.

\subsection{Decomposition}

During supercritical transesterification, the high temperatures (above $573 \mathrm{~K}$ ) employed and long reaction periods, a decrease in the conversion can be observed $[7,57,65-68,73]$.

He et al. [67] evaluated the results obtained for the transesterification of soybean oil in supercritical methanol and concluded that the reason for the decrease in reaction yield is the decrease in the content of unsaturated esters, caused by isomerization, hydrogenation and thermal decomposition that would consume such esters, especially C18:2 (linoleic) and C18:3 (linolenate). Imahara et al. [56] evaluated the thermal stability of different samples of biodiesel and fatty acid esters in different conditions of temperature and pressure. The authors found that thermal degradation is more pronounced for the unsaturated esters above $573 \mathrm{~K}$ and $19 \mathrm{MPa}$ and thermal stability of saturated esters is also affected. Kasim et al. [63] report that the percentage of trans isomers can reach levels up to $16 \%$ under certain reaction conditions $(30 \mathrm{MPa}, 573 \mathrm{~K}$ ) for the transesterification of rice bran oil in methanol. 
At the supercritical reaction conditions, side reactions with the participation of the glycerol formed as byproduct can cause the degradation of other components present in the reaction medium. For instance, Anistescu et al. [61] performed the alcoholysis reactions using supercritical methanol at temperatures around 623-673 $\mathrm{K}$ and reported the absence of glycerol in the reaction products, the authors cogitated that reaction of glycerol with other compounds may have occurred. Aimaretti et al. [62] evaluated the reaction of refined soybean oil with supercritical methanol at different reaction conditions and at the conditions studied by the authors, glycerol was not formed. It is reported that glycerol is converted into lower molecular weight products and water at the beginning of the reaction and that water reacts with triglyceride to form free fatty acid, thus increasing the acidity of the product. In the course of the reaction, these fatty acids are converted into methyl esters. Also, the glycerol may react in different ways: (i) decomposition to produce products of lower molecular weight, such as acrolein, acetaldehyde, acetic acid, among others, (ii) polymerization to form polyglycerols, which occur at high temperature conditions and (iii) etherification with methanol to produce ethers of glycerol, thus consuming the alcohol in the reaction medium. Lee et al. [90], in the synthesis of biodiesel from waste canola oil, reported that side reaction was obtained by reacting glycerol and supercritical methanol at $543 \mathrm{~K} / 10 \mathrm{MPa}$ for 15 , 30 and 45 minutes. The experimental results showed that these reactions could positively affect the overall biodiesel yield by providing oxygenated compounds such as 3methoxy-1,2-propanediol, dimethoxymethane, and 2,2-dimethoxypropane as well methyl palmitate and methyl oleate.

In Vieitez et al. [57] a novel and simple GC method was proposed to evaluate de percentage of overall decomposition. Samples were treated with $\mathrm{BF}_{3} / \mathrm{MeOH}$ [91] to derivatize all of the fatty acids (mono-, di-, and triglycerides, free fatty acids, and also ethyl esters) to the corresponding methyl esters, and then analyzed by GC. For the evaluation of the degradation percentage, palmitic acid was assumed not liable to degradation, considering its high stability, and was taken as reference (as an internal standard "native"). Thus, degradation was estimated as:

Decomposition $(\%)=100 \times\left[1-\left(\frac{\sum P_{i}}{P_{16: 0}}\right)_{S} \times\left(\frac{P_{16: 0}}{\sum P_{i}}\right)_{O}\right]$

where $\Sigma \mathrm{Pi}$ was the summation of all fatty acid methyl ester percentages, P16:0 was the percentage of 16:0 ethyl ester, and subscripts " $\mathrm{s}$ " and "o" indicate that the expressions between brackets were evaluated considering the composition of the sample product and the original oil, respectively [57].

The use of the term "decomposition" of fatty acids referred to the decrease in its percentage (determined by gas chromatography) due to the formation of other compounds (not necessarily imply that they have "broken" but have suffered some type of alteration). Since there is no information about the determination of this parameter type, the method described below can be considered a new contribution to the area of the synthesis of biodiesel in supercritical alcohols. 


\subsection{Addition of co-solvent}

A question to be considered is the addition of co-solvents to the reaction medium that can provide milder operation conditions, since the use of co-solvents reduces the limitations of mass transfer between phases involved [92] and increases the reaction rate offering an homogeneous reaction media $[69,70]$.

As co-solvents in supercritical transesterification it can be used non-polar compressed gases, for example, carbon dioxide, methane, ethane, propane, n-butane and their mixtures [92]. Some studies have reported the use of heptane/hexane as co-solvent [93-95]. Among these the use of $\mathrm{CO}_{2}$ at supercritical conditions has shown a promising future for environmentally friendly chemical processes, because it comprises a nonflammable solvent, nontoxic, inexpensive and readily available in high purity. Indeed, besides being a good solvent for extraction, carbon dioxide has also proved useful as solvent reaction medium [96]. However, a limiting factor for the use of carbon dioxide is low mutual solubility $\mathrm{CO}_{2}$-triglycerides, which means that high pressures are required to solubilize the reagents [97].

The use of propane and n-butane as compressed solvent or even in the supercritical state seems to be a nice substitute for a variety of solvent in reactive systems. These gases offer as the main advantage the low pressure transitions systems found mainly in vegetable oils due to the higher solubility exhibited compared to that the use of $\mathrm{CO}_{2}[97,98]$. Pereda et al. [99] reported that the use of propane in the hydrogenation of triglycerides increases the miscibility of the components of the mixture, allowing the reaction to occur under conditions of a single homogeneous phase.

Yin et al. [72] reported that esters yield for the reaction using supercritical methanol increased when using carbon dioxide as cosolvent. Imahara et al. [93], in the alcoholysis of canola oil in methanol with the addition of supercritical $\mathrm{CO}_{2}$, found that the addition of cosolvent increases the reaction yield, however, high molar percentage of $\mathrm{CO}_{2}$ (above $0.1 \mathrm{CO}_{2}$ / methanol) led to a decrease in reaction conversion.

\subsection{Two-step reaction}

Based on the reports available in the literature it is suggested that the transesterification of vegetable oils at supercritical conditions can be conducted on alternative systems in order to reduce raw material costs and operating costs. There is a growing emphasis on the proposed system with a two-step reaction using reactors in series, with higher conversions to the system in one step [66] at mild operating temperatures and pressures and decreasing the amount of alcohol used in the process [87].

Kusdiana \& Saka [65] and Minami \& Saka [66] proposed the continuous synthesis of biodiesel from canola oil in two reaction steps, which consists primarily in the hydrolysis of triglycerides in pressurized water and subsequent esterification of fatty acids in supercritical methanol, with glycerol removed prior to FFA methyl esterification. This process is carried out under more moderate temperature and pressure compared to the process in one step. 
Busto et al. [100] reported that tubular reactors for supercritical transesterification must operate in order to minimize the axial dispersion, and as suggested by the authors, to satisfy this condition: reactions in a tubular reactor with separation step of unreacted products, with recycle the same or two or more reactors in series with intermediate separation of glycerol generated. One advantage of removing the glycerol formed in the reaction mixture is to allow the reaction to occur at lower ratios of alcohol to oil increasing the reaction rate for the production of biodiesel [87]. As cited by Aimaretti et al. [62], along the reaction, the alcohol used in the process is required by secondary reactions, which occur with glycerol.

D'Ippolito et al. [75] evaluated theoretically the non-catalytic process for producing biodiesel from experimental data and information available in the literature to determine an operating mode and operating conditions that reduce energy consumption and increase product quality. Results obtained suggest that the two-step process with intermediate removal of glycerol decreases the ratios of methanol to oil to about 10-15 times. Furthermore, not only the system pressure can be reduced as energy costs. In the process proposed by Crawford et al. [87], it is suggested that the obtained esteres by supercritical route can be made by transesterification of triglycerides with continuous removal of glycerol formed in the process, periodically or continuously, increasing the rate of ester formation. These authors argued that the reaction proceeded in this way can greatly decrease the amount of alcohol to be used in the process.

\subsection{Intensification technologies in continuous biodiesel production}

In the transesterification of vegetable oils, reaction rate can be limited by mass transfer between oil and alcohol because the very poor mutual miscibility. Hence, some process intensification technologies have been developed and applied to improve mixing and mass/heat transfer between the two liquid phases in recent years. Reaction rate is greatly enhanced and thus residence time may be reduced. Some of the technologies have been applied successfully in commercial production [101]. To reduce the limitations of mass and heat transfer in chemical reactions, literature indicates to conduct these reactions in microreactors [102-105] and in packed bed reactors [106-109].

In microreactors, mass and heat transfer increase due to the small size and large contact area [110] and the lowest internal diameters promote interaction with the reagents at the molecular level [111]. The internal diameter of microreactors, are typically10-300 $\mu \mathrm{m}[102,103]$. Sun et al. [109] used reactors with 0.025 to $0.053 \mathrm{~cm}$ inner diameter and Guan et al. [112] used reactors with different inner diameters: $0.04,0.06,0.08$ and $0.1 \mathrm{~cm}$, calling them as microtube reactors. Furthermore, higher conversion and selectivity are obtained in a shorter reaction time as compared to batch system [102,113].

The rates of transesterification for biodiesel production are controlled by the rate of mass transfer between phases [112], being applied high rates of agitation for the batch system. Sun et al. [109] studied the production of biodiesel using alkaline catalysis with capillaries microreactors, and reported that the residence time is significantly reduced by the use of these reactors compared to the conventional process in batch 
mode. Guan et al. [112] investigated the synthesis of biodiesel using microtube reactors for the alcoholysis of sunflower oil by basic catalysis, evaluating the influence of the length and internal diameter of the reactor. The conversion of the oil was strongly influenced by reactor geometry and the best results were obtained for the reactor with smaller diameter and greater length.

Although the phenomenon related to mass transfer is a key parameter to obtain better yields in biodiesel by the supercritical method and one approach suitable is the use of packed bed reactor. The packed bed system maximizes the interfacial surface area between the two phases (oil and alcohol) and the contact of the immiscible liquid-liquid two phases are improved towards achieving excellent mass transfer performance, which is obtained by extruding one phase into another, as the two phases flow through the particles openings, as commonly found in a packed bed reactor [106,114, 115].

Ataya et al. [106] reported the acid-catalyzed transesterification of canola oil with methanol using a packed bed reactor and showed that the mass-transfer limitations for twophase experiments can be effectively overcome using a liquid-liquid packed bed reactor. Santacesaria et al. [108] performed the transesterification reactions in a simple tubular reactor filled with stainless steel spheres of different sizes and obtained that the reactions like methanol-soybean oil transesterification, mass transfer rate can greatly be increased also by favoring an intense local turbulence. The effects of packed bed reactor can be observed in other chemical reactions, for instance, Su et al. [115] evaluated the effect of packed microchannel reactors to perform the nitration of o-nitrotoluene with mixed acid and reported that the yield of this liquid-liquid multiphase reaction is increased by conducting the reaction using the packed reactor.

\section{Configuration of reactors in continuous mode for supercritical ethanolysis}

The following sections are dedicated to provide an overview of results obtained in supercritical ethanolysis in different reactor configurations. The schematic diagram of the experimental setup, developed by our research group, is shown in Figure 2. In these experiments, the residence time was simply computed dividing the volume of the reactor $(\mathrm{mL})$ by the flow rate of substrates $(\mathrm{mL} / \mathrm{min})$ set in the liquid pump.

Results reported are in relation to content of esters in the sample determined by gas chromatography, following the European normative EN 14103 [116]. The data related to decomposition refer to derivatization of the samples with $\mathrm{BF}_{3} /$ methanol [91] to derivatize all of the fatty acids (mono-, di-, and triglycerydes, free fatty acids, and also ethyl esters) to the corresponding methyl esters and then analyzed by gas chromatography. For the evaluation of the decomposition percentage, palmitic acid was assumed not liable to degradation, considering its high stability $[56,67]$. These experimental procedures as well as analytical methods used are described in detail in the work of Vieitez et al. [57] and Silva et al. [79]. 


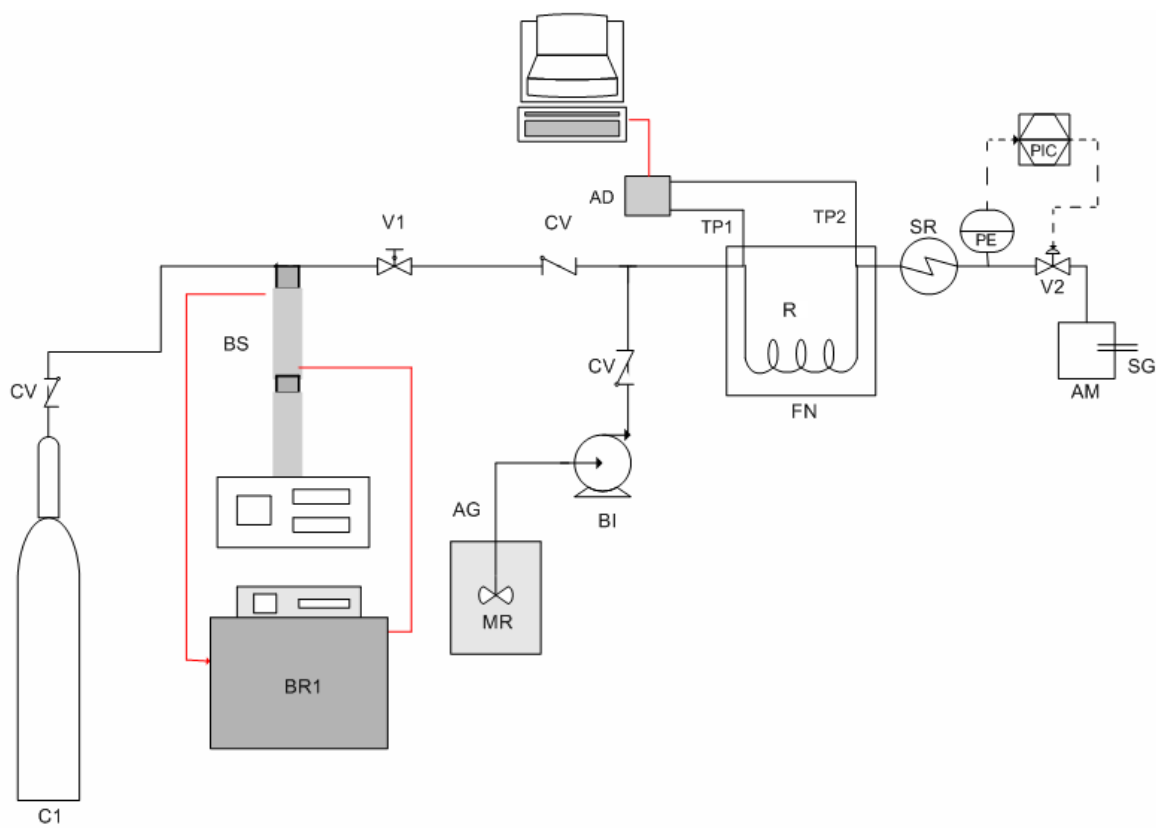

Figure 2. Schematic diagram of the experimental apparatus. RM - reactional mixture; MS - mechanical stirring device; LP - high-pressure liquid pump; CV - check-valve; A - solvent reservoir; B - thermostatic baths; SP - syringe pump; F furnace; R - reactor; T1 - temperature indicator at the reactor inlet; $\mathrm{T} 2$ - temperature indicator at the reactor outlet; DA - data acquisition system; CS - cooling system; V1 - feed valve; PI - pressure indicator; PIC - controller; V2 - pressure control valve; S - glass collector; G - gas output. Taken with permission from Silva et al. [79].

\subsection{Tubular reactor}

The tubular reactor utilized was made of stainless steel tubing (316L 1/4 in. OD internal diameter of $3.2 \mathrm{~mm} \mathrm{HIP),} \mathrm{being} \mathrm{used} \mathrm{in} \mathrm{the} \mathrm{work} \mathrm{of} \mathrm{Silva} \mathrm{et} \mathrm{al.} \mathrm{[68],} \mathrm{Vieitez} \mathrm{et} \mathrm{al.} \mathrm{[57],} \mathrm{Vieitez}$ et al. [7], Bertoldi et al. [73], Vieitez et al. [117], Vieitez et al. [58], Vieitez et al. [118], Silva et al. [77], Vieitez et al. [119] and Vieitez et al. [120]. In these works, several approaches were made in order to optimize transesterification reactions for biodiesel production in supercritical ethanol in continuous tubular reactor and the better yields achieved for each study are presented in Table 1.

Silva et al. [68] investigated the effect of the variables temperature, pressure, oil to ethanol molar ratio and residence time on the yield of ethyl esters in the transesterification reaction of refined soybean oil. In that work, it was observed that an increase in temperature led to a sharp enhancement of reaction conversions and faster initial reaction rates. Also, as reaction time develops, a decline in the conversion reaction was observed for the temperature of $648 \mathrm{~K}$. The reaction pressure had influence on the FAEE yields, with better yields obtained at $20 \mathrm{MPa}$. Regarding the effect of oil to ethanol molar ratio, results obtained by that study demonstrated that after a certain period of time higher values of molar ratio of ethanol to oil afford better con- 
versions in shorter reaction times. This fact could be expected to a certain extent because in catalyst-free reactions an increase in the alcohol-to-oil molar ratio should provide greater contact between substrates, thus favoring reaction conversion. Besides, an excess of reactant could also shift the reaction to ethyl esters formation. In the experimental range investigated the authors reported $\sim 80 \%$ in ethyl esters at the operating conditions shown in Table 1 .

\begin{tabular}{|c|c|c|c|c|}
\hline Vegetable oil & Conditions and additional information & $\begin{array}{c}\text { FAEE yield } \\
\text { [\%] }\end{array}$ & $\begin{array}{c}\text { Decomposition } \\
{[\%]}\end{array}$ & Reference \\
\hline $\begin{array}{l}\text { Refined } \\
\text { soybean oil }\end{array}$ & $\begin{array}{l}\text { 1:40 oil to ethanol molar ratio; } 623 \mathrm{~K} ; 20 \mathrm{MPa} \text {; } \\
35 \mathrm{~min}\end{array}$ & $\sim 80.0$ & NR & {$[68]$} \\
\hline $\begin{array}{l}\text { Refined } \\
\text { soybean oil }\end{array}$ & $\begin{array}{l}1: 40 \text { oil to ethanol molar ratio; } 623 \mathrm{~K} ; 20 \mathrm{MPa} ; \\
28 \mathrm{~min} \text { and water content of } 2.5 \mathrm{wt} \%\end{array}$ & 70.0 & $\sim 14.0$ & \multirow{2}{*}[57]{} \\
\hline $\begin{array}{l}\text { Refined } \\
\text { soybean oil }\end{array}$ & $\begin{array}{l}1: 40 \text { oil to ethanol molar ratio; } 623 \mathrm{~K} ; 20 \mathrm{MPa} \text {; } \\
28 \mathrm{~min} \text { and water content of } 2.5 \mathrm{wt} \%\end{array}$ & 70.0 & $\sim 14.0$ & \\
\hline $\begin{array}{l}\text { Refined } \\
\text { soybean oil }\end{array}$ & $\begin{array}{l}\text { 1:40 oil to ethanol molar ratio; } 573 \mathrm{~K} ; 20 \mathrm{MPa} \text {; } \\
52.5 \text { min and water content of } 5 \mathrm{wt} \%\end{array}$ & 70.0 & 3.0 & [7] \\
\hline $\begin{array}{l}\text { Degummed } \\
\text { soybean oil }\end{array}$ & $\begin{array}{l}1: 40 \text { oil to ethanol molar ratio; } 623 \mathrm{~K} ; 20 \mathrm{MPa} \text {; } \\
28 \mathrm{~min} \text { and water content of } 10 \mathrm{wt} \%\end{array}$ & 55.0 & NR & [117] \\
\hline Castor oil & $\begin{array}{l}\text { 1:40 oil to ethanol molar ratio; } 573 \mathrm{~K} ; 20 \mathrm{MPa} \text {; } \\
28 \mathrm{~min} \text { and water content of } 5 \mathrm{wt} \%\end{array}$ & 75.0 & $\sim 11.0$ & {$[58]$} \\
\hline Sunflower oil & $\begin{array}{l}\text { 1:40 oil to ethanol molar ratio; } 623 \mathrm{~K} ; 20 \mathrm{MPa} \text {; } \\
42 \mathrm{~min} \text { and water content of } 5 \mathrm{wt} \%\end{array}$ & $\sim 69.0$ & $\sim 14.0$ & \multirow{2}{*}{ [119] } \\
\hline $\begin{array}{l}\text { High oleic } \\
\text { sunflower oil }\end{array}$ & $\begin{array}{l}\text { 1:40 oil to ethanol molar ratio; } 623 \mathrm{~K} ; 20 \mathrm{MPa} \text {; } \\
42 \mathrm{~min} \text { and water content of } 5 \mathrm{wt} \%\end{array}$ & $\sim 75.0$ & $<5.0$ & \\
\hline $\begin{array}{l}\text { Refined } \\
\text { soybean oil }\end{array}$ & $\begin{array}{l}\text { 1:40 oil to ethanol molar ratio; } 573 \mathrm{~K} ; 20 \mathrm{MPa} ; \\
\sim 48 \text { min and addition of } 10 \% \text { of free fatty } \\
\text { acids to oil }\end{array}$ & 90.0 & $<5.0$ & \multirow{3}{*}{ [120] } \\
\hline $\begin{array}{l}\text { High oleic } \\
\text { sunflower oil }\end{array}$ & $\begin{array}{l}\text { 1:40 oil to ethanol molar ratio; } 623 \mathrm{~K} ; 20 \mathrm{MPa} ; \\
\sim 48 \text { min and addition of } 10 \% \text { of free fatty } \\
\text { acids to oil }\end{array}$ & 85.0 & $\sim 8.0$ & \\
\hline Rice bran oil & $\begin{array}{l}\text { 1:40 oil to ethanol; } 573 \mathrm{~K} ; 20 \mathrm{MPa} ; 26 \mathrm{~min} \text { and } \\
\text { addition of } 10 \% \text { of free fatty acids to oil }\end{array}$ & 82.0 & $<5.0$ & \\
\hline $\begin{array}{l}\text { Refined } \\
\text { soybean oil }\end{array}$ & $\begin{array}{l}\text { 1:40 oil to ethanol molar ratio; } 598 \mathrm{~K} ; 20 \mathrm{MPa} \text {; } \\
110 \text { min and } \mathrm{CO}_{2} \text { to substrates mass ratio of } \\
0.05: 1\end{array}$ & 76.0 & NR & [73] \\
\hline $\begin{array}{l}\text { Refined } \\
\text { soybean oil }\end{array}$ & $\begin{array}{l}\text { 1:1 oil to ethanol mass ratio; } 598 \mathrm{~K} ; 20 \mathrm{MPa} \text {; } \\
30 \text { min and operated with two reactors in } \\
\text { series }\end{array}$ & 74.0 & $\sim 5.0$ & \multirow[t]{2}{*}[77]{} \\
\hline & $\begin{array}{l}\text { 1:1 oil to ethanol mass ratio; } 598 \mathrm{~K} ; 20 \mathrm{MPa} ; \\
30 \text { min and operated with recycle of } 40 \mathrm{wt} \%\end{array}$ & 75.0 & $\sim 4.0$ & \\
\hline
\end{tabular}

Table 1. Comparison of results obtained for transesterification reactions with supercritical ethanol in tubular reactor. 
Industrial scale synthesis of biodiesel generally relies on the transesterification of vegetable oils with a short-chain alcohol, mainly methanol, using chemical catalysts [12]. Because ethanol is readily available from fermentative processes using biomass from a varied source, ethanol biodiesel appears as a 100\% renewable alternative, additionally enabling the replacement of traditionally used methanol by an innocuous reagent. Besides, in the Brazilian context, ethanol has been the natural choice because Brazil is one of the biggest ethanol producers in the world, with a well established technology of production and large industrial plant capacity installed throughout the country. However, the cost of ethanol is still higher than that of methanol, in particular where absolute (dry) ethanol is used in processes based on conventional catalytic methods $[1,3]$.

Adopting the best experimental conditions (soybean oil to ethanol molar ratio of 1:40, $623 \mathrm{~K}$ and $20 \mathrm{MPa}$ ) reported by Silva et al. [68], Vieitez et al. [57] evaluated the effect of water content $(2.5 \mathrm{wt} \%$ to $10 \mathrm{wt} \%)$ on the reaction yield. Results showed that the presence of water in the reaction medium seems to have a positive effect on the FAEE production. A significant increase in the ester content was observed for 598, 573, and $548 \mathrm{~K}$ for all residence time studied, suggesting that reaction conversions should be improved by the presence of water in the reaction medium. No relevant changes were observed corresponding to $623 \mathrm{~K}$, probably due to the persistence of side degradation reactions. A moderate increase in the ester content also was found for the reaction performed at $523 \mathrm{~K}$, which seemed to be the minimum temperature value that should be considered for conducting catalyst-free transesterification reactions under supercritical conditions. For all values of water content in the reaction medium, a point of maximum of ester yield was found within the residence time range investigated. The maximum FAEE concentration was found at 28 minutes of residence time for water content values of $0,2.5$, and $5 \%$, while higher values of water content $(7.5$ and $10 \%$ ) showed a maximum ester content for 42 minutes of residence time. The maximum point of ester content was positively affected by the presence of water in the reaction medium; i.e., at $300^{\circ} \mathrm{C}$ and $52.5 \mathrm{~min}$, an increase in water content from 0 to $5 \%$ led to an increase in FAEE concentration from 29.7 to $70.0 \%$, respectively. Therefore, the presence of water in the reaction medium showed a favorable effect on the ester synthesis, due to its possible catalytic role for the transesterification process and reduction of fatty acids degradation [7].

As observed by Silva et al. [68], a decrease in reaction yield by increasing the reaction time was found. As shown in Figure 3 [57], significant differences were noticed between the fatty acid composition of the starting soybean oil compared to that of the original product, involving the reduction in the polyunsaturated fatty acid ethyl ester percentage (C18:1, C18:2 e C18:3) and the production of trans isomers, originally absent (Figure 3). Also, the authors reported high percentage of fatty acid decomposition in the temperature of study (623 K). For yields $>80 \%$ about $12 \mathrm{wt} \%$ of decomposition was observed and about $4.0 \%$ of triglycerides for system without addition of water.

Considering the occurrence of fatty acids decomposition at high residence times and the formation of isomers of ethyl esters formed, Vieitez et al. [7] reported the effect of temperature $(523 \mathrm{~K}$ to $623 \mathrm{~K})$ and water content $(5 \mathrm{wt} \%$ to $10 \mathrm{wt} \%$ ) on these factors and yield of esters. It was observed that temperature strongly affected the degree of degradation with values of 
about $12 \mathrm{wt} \%$ and $28 \mathrm{wt} \%$ at $598 \mathrm{~K}$ and $623 \mathrm{~K}$, respectively, for addition of $5 \mathrm{wt} \%$ of water in the reaction medium and high residence times. Moreover, the degradation phenomenon decreased as water concentration increased from $0 \mathrm{wt} \%$ to $10 \mathrm{wt} \%$.

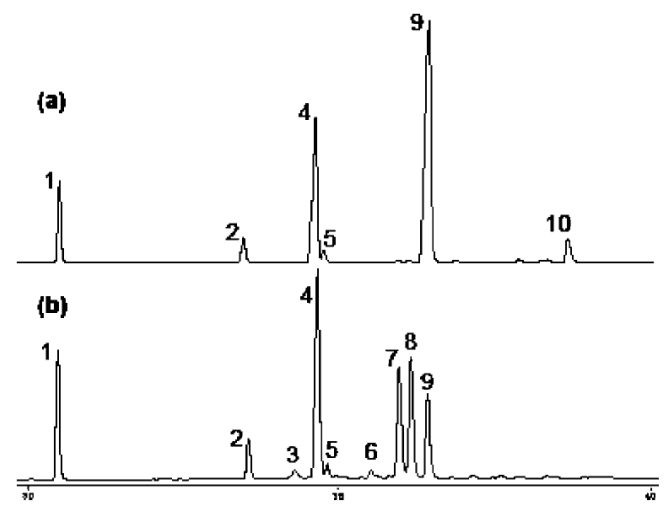

Figure 3. GC analysis of (a) soybean oil and (b) the product of the reaction (processed oil) performed at $350{ }^{\circ} \mathrm{C}, 20$ $\mathrm{MPa}, 0 \%$ water, oil to ethanol molar ratio of $1: 40$ and 28 min of residence time. Peaks identification: C16:0 (1), C18:0 (2), trans-C18:1 (3), cis-9-C18:1 (4), cis-11-C18:1 (5), trans-6,12-C18:2 (6), cis-6,trans-12-C18:2 (7), trans-6,cis-12-C18:2 (8), cis-6,cis-12-C18:2 (9), and cis-9,12,15-C18:3 (10). Taken with permission from Vieitez et al. [57].

With respect to the effect of water concentration in the reaction medium on the degradation level, it was observed that the degradation phenomenon decreased as water concentration increased from 0 to $10 \mathrm{wt} \%$. This reduction is in agreement with results showing that the addition of water may provide lower degradation levels and, accordingly, higher reaction conversions. Although no previous studies under similar conditions were found, these results are in agreement with some available references concerning the well-known favorable effect of the relatively low water activity on the oxidative stability of methyl linoleate or of vegetable oils. This phenomenon was attributed to different mechanisms, like the bonding of hydroperoxides, which decreases their reactivity, and an antioxidant effect due to hydration of traces of metals, which reduces their catalytic action [7].

The feedstock flexibility is the most important advantage to consider for biodiesel production methods because the resultant biodiesel price strongly depends on the feedstock price $[121,122]$. The cost of the raw materials currently represents about $70 \%$ of the total production cost [11]. The free fatty acids and water content in low grade feedstocks and hydrated ethanol pose a negative effect on the conventional homogeneous alkali-catalyzed process and heterogeneous catalytic methods, but can be successfully used in the transesterification reaction using an alcohol at its supercritical conditions. The evaluation of the effect of these variables on the efficiency of the transesterification reaction is highlighted. As shown in previous studies, the water content promotes the conversion of esters and decreases the degree of decomposition. Regarding the quality of the vegetable oil, studies concerning the effect of the vegetable oil type and free fatty acid content should be performed. 
While growth within the biodiesel sector can contribute to increase the price of soybean oil and other biodiesel source materials, the competitiveness of the sector can be adversely affected by these very same prices changes, as well as other economic factors. These emerging trends suggest that food and energy markets are likely to be more strongly linked in future such that spikes and fluctuations in the prices of energy lead to corresponding changes in food prices [123]. Currently, the main resource for biodiesel production in Brazil is soybean oil, comprising about $80 \%$ of total feedstock [124], however, recently raw material price increases has motivated the use other raw materials towards a future global leadership of the country in biodiesel production and use of non-edible and waste oils with low-added value.

The ethanolysis of degummed soybean oil was reported by Vieitez et al. [117] to evaluate the use of alternative raw materials in order to reduce the production costs. The experiments were performed at $20 \mathrm{MPa}, 623 \mathrm{~K}$ and oil to ethanol molar ratio of 1:40 and lower ester contents were obtained with degummed oil than from using refined oil. At 28 minutes of residence time about $\sim 80 \%$ and $40 \%$ of esters were obtained for refined and degummed oil, respectively. Many possible reasons for these results are mentioned by the authors, like the possible adverse effect of some minor components with a higher concentration in the degummed oil, e.g. pigments or hydroperoxides, with a known pro-oxidant effect on the fatty acids.

In the same context, to in the search of low-cost raw materials, alternative to refined soybean oil, Vieitez et al. [58] evaluated the possibility of producing ethyl esters from castor oil, a plant considered interesting as a potential raw material for biodiesel production. The effect of temperature ( $523 \mathrm{~K}$ to $623 \mathrm{~K}$ ) and water content ( $5 \mathrm{wt} \%$ to $10 \mathrm{wt} \%$ ) was evaluated by keeping the pressure fixed at $20 \mathrm{MPa}$ and oil to ethanol molar ratio of 1:40. The authors reported FAEE yields in the order of $75 \%$ at $573 \mathrm{~K}, 5 \mathrm{wt} \%$ of water content and 28 minutes of residence time. The authors emphasized that special care should be taken into account concerning reaction temperature, which could favor the occurrence of side reaction involving the consumption of high percentage do fatty acids when increased over 573K. For example, it was related $>70.0 \%$ of decomposition at $623 \mathrm{~K}$ for high residence times ( $>28$ minutes).

In a later study, Vieitez et al. [119] focused on the dependence of esters yield and decomposition as a function of vegetable oil composition (Table 2). The results obtained show a relation between the composition of vegetable oil and content of esters. Note that the content of esters, regardless of residence time considered, decreases in the following order: high oleic sunflower oil> sunflower oil > soybean oil> castor oil. This order, except by castor oil, is inversely with the degree of unsaturation of each oil, which confirms that the efficiency of the process dependency of the stability of the oil used. The castor oil has a high percentage of decomposition. This percentage increases in the following order for the vegetable oils studied: high oleic sunflower oil < sunflower oil < soybean oil $<<$ castor oil.

Considering that decomposition phenomenon may strongly affect the ester yield and that the chemical stability is mainly determined by the insaturation degree of the fatty material, it is of major interest to study the behavior of oils with different fatty acid compositions in this process. Table 2 shows the composition of the different oils studied and their corresponding iodine value (IV), which indicates concerning solely the fatty acid composition, HO-SFO should be the oil with the higher stability (lower IV), followed by SFO and SBO. 


\begin{tabular}{ccccc}
\hline Fatty acid & Soybean oil & Castor oil & Sunflower oil & High oleic sunflower oil \\
\hline $16: 0$ & 10.9 & 1.0 & 6.2 & 3.5 \\
\hline $18: 0$ & 3.5 & 0.9 & 3.3 & 2.5 \\
\hline $18: 1$ & 26.0 & 3.4 & 32.0 & 87.4 \\
\hline $18: 2$ & 52.7 & 4.6 & 56.3 & 4.7 \\
\hline $18: 3$ & 5.0 & 0.4 & 0.4 & 0.2 \\
\hline $18: 1-\mathrm{OH}$ & ---- & --- & 85.3 \\
\hline IV & 129.2 & --- & 128.5 & \\
\hline
\end{tabular}

Table 2. Fatty acid composition (wt\%) of de vegetable oils studied. ((a)IV was calculated according method AOCS Cd $1 c-85[125])$

The decomposition phenomenon was also studied in the work of Vieitez et al. [118], in which the stability of ethyl esters from soybean oil (SBOEE) exposed to high temperatures in supercritical ethanol was determined. In order to separately study the effect of such phenomenon, pure SBOEE were mixed with ethanol at a molar ratio 40:3 (ethanol:SBOEE) and exposed for different periods to supercritical conditions in a continuous system, at $20 \mathrm{MPa}$ and different temperatures. It was experimentally observed that the ester content of the processed samples were lower than that corresponding to the original SBOEE, indicating the occurrence of decomposition processes, which were more important as the temperature and residence time increased. The content of polyunsaturated esters of the treated SBOEE was lower than that of the starting mixture, showing that the decomposition rate was highly dependent on the nature and instauration degree of the alkyl chain. Therefore, results show that the exposure of the SBOEE to severe conditions required for efficiently performing the ethanolysis of vegetable oils by the supercritical method could cause the occurrence of important degradation processes of the lipid material. Such phenomenon could be identified as the main reason why the products from the supercritical transesterification of oils are less unsaturated than the raw materials. According to the results, the decomposition phenomenon is "selective" towards the polyunsaturated fatty esters, and there are no reasons to attribute such selectivity to the transesterification itself. Results also suggest that, in terms of the preservation of the integrity of the fatty acid chain, a supercritical transesterification process should not be performed at temperatures above $573 \mathrm{~K}$, due to the high increase in the decomposition rate.

Recently, Vieitez et al. [120] evaluated the effect of the concentration of free fatty acids (FFAs) and type of vegetable oil on the yield of the reaction and decomposition of fatty acids. That work studied the effect of the addition of FFAs at various proportions to different vegetable oils (soybean oil, rice bran oil, and high oleic sunflower oil) on the efficiency of their conversion to ethyl esters by a continuous supercritical ethanolysis. When the reactor was operated at $573 \mathrm{~K}$ and $20 \mathrm{MPa}$ with soybean oil using an alcohol/oil molar ratio of 40:1, an ester content of $53 \%$ was obtained. Under identical conditions but processing soybean oil with $10 \%$ of FFAs, the ester content rose to $91 \%$. A similar favorable effect of the addition of 
FFAs on the efficiency of the process was observed when processing rice bran oil and high oleic sunflower oil. Processing oils from different origins may lead to different ester contents in the final product because of the occurrence of decomposition phenomenon at different extents depending upon oil composition and stability. Results showed that the addition of FFAs is a useful tool for favoring alcoholysis against decomposition, with the consequence of a substantial increase in process efficiency. Therefore, the addition of FFAs could be a useful for improving the supercritical transesterification of oils with a low initial acidity and low-quality fats, such as highly hydrolyzed RBO, which could be efficiently converted to biodiesel using this technology. Several favorable effects on the process can be attributed to the presence of high levels of FFAs in the raw material: a catalytic role in the transesterification of triacylglycerides, a high esterification rate of FFA themselves, and a dilutive effect on the glycerol in the reaction medium (thus avoiding several unwanted side reactions). The contribution of all of these factors permitted us to achieve high efficiencies even at milder reaction conditions, thus minimizing the decomposition phenomenon, which has been pointed out as one of the main drawbacks of the supercritical method [119].

As observed in the studies presented in Table 1, the high transesterification conversion requires high temperature, high pressure and high alcohol to oil molar ratio. Indeed, the high temperature and pressure require high initial investments (equipment costs) for the implementation of such process operated and safety management policy. As a result of the high alcohol to oil molar ratio greater energy consumption in the reactants pre-heating and recycling steps is unavoidable. Moreover, the high amount of alcohol in the biodiesel product retards the biodiesel-glycerol phase separation. Therefore, the use of those original parameters results in high capital costs, especially for the reactor and pump, being somewhat higher than the novel catalytic methods [126]. To increase the technical and economical feasibility of supercritical method, further studies are required to reduce the energy consumption and operating parameters of this process.

In an attempt to reduce the operating conditions of the transesterification reaction, Bertoldi et al. [73] proposed for the first time the addition of carbon dioxide as a co-solvent in the reaction medium for reactions in continuous mode. The experiments were performed in the temperature range of 573-623 K, from 7.5 to $20 \mathrm{MPa}$, oil to ethanol molar ratio of 1:10 to 1:40 and co-solvent to substrates mass ratio from $0: 1$ to $0.5: 1$. Results showed that the yield of ethyl esters decreased with increasing addition of carbon dioxide to the system. At $623 \mathrm{~K} ; 20$ MPa; oil to ethanol molar ratio of 1:40 and $35 \mathrm{~min}$ it was observed about $80 \%$ of esters yield for system without co-solvent [68] and about $40 \%$ for addition of $\mathrm{CO}_{2}$ to substrates mass ratio of $0.05: 1$. Phase equilibrium data for the binary system ethanol- $\mathrm{CO}_{2}$ shows the existence of high mutual solubility for these compounds $[127,129]$. On the other hand, very poor solubility of carbon dioxide in soybean oil has been reported in the literature [97]. Thus, it is possible that the co-solvent is dragging some amount of ethanol from the oil phase, causing the occurrence of a two-phase flowing system, decreasing the content of ethanol in contact with the vegetable oil with a consequent reduction in reaction conversion.

Another proposal considered was the non-catalytic production of fatty acid ethyl esters from soybean oil in a two-step process with experimental simulation of two reactors operat- 
ed in series and a reactor with recycle, reported by Silva et al. [77]. The justification of the authors refers to the reaction conducted in two steps with reactors in series and/or recycling the leaving stream with intermediate removal of glycerol can increase the yield of the reaction, since the reaction may take place at lower alcohol to oil ratios, increasing the reaction rates of ester production [87]. The reaction of glycerol formed during the process with other components of the reaction medium may lead to a decrease in ester yield [66] and the undesirable consumption of alcohol [62,90]. Another important point of conduction of reactions in two steps is that the non-reacted products, diglycerides and monoglycerides, and also the esters formed may act as co-solvents in the reaction medium, increasing the solubility between the phases $[100,130]$. For the reactor in series it was reported $74 \%$ in esters at $598 \mathrm{~K}, 20$ $\mathrm{MPa}$, oil to ethanol mass ratio of 1:1 and 30 minutes of residence time for the second reaction step. For the system with recycle of $40 \mathrm{wt} \%$ at similar conditions it was obtained $75 \%$. In both cases the degree of decomposition was lower than $5.0 \%$.

\subsection{Microtube reactor}

Microreactor systems designed for continuous production have been studied in recent years for the transesterification of vegetable oils $[109,112]$. In the microreactor system, mass and heat transfer could be greatly intensified due to its small space with a large surface area-tovolume ratio [112], providing high process yields in low reaction times [109].

In this context, Silva et al. [79] developed a microtube reactor of stainless steel tubing (316L $1 / 16$ in. OD internal diameter of $0.76 \mathrm{~mm} \mathrm{HIP)}$ to evaluate the effects of inner diameter on the FAEE yield and compare the results with those reported by Silva et al. [68] for the same conditions using a tubular reactor. At lowest temperature (523 K) only $3.12 \%$ FAEE yield is obtained in the tubular reactor, while $19 \%$ is reached using the microtube reactor. At $598 \mathrm{~K}$ this yield is increased from $38 \%$ to $53 \%$ when changing from the tubular to the microtube reactor at the same residence time. Such results demonstrate that higher ethyl esters yields can be achieved at lower temperatures, short reaction times with a smaller reactor inner diameter, hence minimizing the total decomposition of fatty acids.

In the work of Silva et al. [79] it was evaluated the effect of process variables (temperature, pressure and oil:ethanol molar ratio) on the yield of esters and decomposition. It was found that this variable had a positive effect on FAEE yield. In that work, it was noticed that an increase pressure and lowest ratios of ethanol to oil led to higher degrees of decomposition. It was also observed higher decomposition rates for oil:ethanol molar ratio of 1:10 and pressure of $20 \mathrm{MPa}$. In the experimental range investigated, appreciable yields were obtained $(70 \%)$ at $598 \mathrm{~K}, 20 \mathrm{MPa}$ and oil to ethanol molar ratio of 1:20, with low total decomposition of fatty acid $(<5.0 \mathrm{wt} \%)$.

Considering the increasing reaction rates and improved mass transfer between phases in the conduction of reactions in a microtube reactor and the results obtained by Bertodi et al. [73] when using a cosolvent for the continuous tubular reactor, Trentin et al. [74] evaluated the addition of carbon dioxide on the reaction medium of soybean oil transesterification carried out in a microtube reactor. Results showed that ethyl esters yields obtained increased with increasing addition of carbon dioxide to the system and the highest yields were obtained 
with addition of co-solvent to substrate mass ratio of 0.2:1 to the reaction medium. The authors reported that the differences found in relation the conduct of the reactions in the tubular reactor [73] can be attributed to the problems of mass transfer in the tubular reactor and due to the fact that the mass and heat transfer may be greatly enhanced due to the smaller internal space (which means higher fluid velocity at the same flow rate), and the higher surface area-to-volume ratio, leading to higher process yields.

Silva et al. [76], conducted reactions in two steps in a microtube reactor: two-series reactors and reactor with recycle, conducted. It was obtained about $78 \%$ of ethyl esters yields and $<2.0 \mathrm{wt} \%$ of decomposition for $45 \mathrm{~min}$ in the simulation of two reactors operated in series at $573 \mathrm{~K}, 20 \mathrm{MPa}$, oil to ethanol mass ratio of 1:1 (for the one-step process the authors shows 40 $\%$ of ethyl esters in the same conditions at $25 \mathrm{~min}$ ). These results are higher than those reported by Silva et al. [77] at lower temperature and lower decomposition degree, as was also observed for reactions with recycle. Furthermore, in that work, glycerol was obtained with $\sim 90 \mathrm{wt} \%$ of purity (after evaporation of ethanol and simple decantation) for the system with recycle and this fact of course should be taken into account for the purpose of implementation of a cost-effective transesterification process.

\subsection{Packed-bed reactor}

Results presented for the transesterification in microtube reactors are undoubtedly significant. However, production capacities of the above microreactors are considerably lower than those of conventional reactors by reason of their specific structures. Fulfilling the volume requirements of small-fuel biodiesel processing plants for distributive applications seems difficult. It is thus a challenge to identify a method for maximizing high synthesis efficiency by mixing at the microscale as well as for increasing biodiesel production remarkably [107]. An alternative to these problems would be to conduct the reactions in packed-bed reactors filled with different materials in different diameters, such as stainless steel spheres [108], metal foams [107] and glass beads [106].

In the work of Andrade et al. [80] a packed-bed tubular reactor was developed, which was made of stainless steel tubing (316 L 1/4 in OD inner diameter $3.2 \mathrm{~mm}$ ) and stainless steel tubing (304 L $30.5 \mathrm{~mm}$ OD inner diameter $13 \mathrm{~mm} \mathrm{HIP)}$ packed with glass beads (4.5 $\mathrm{mm}$ diameter). The results obtained by authors demonstrate that much higher ethyl esters yields can be achieved with this configuration. It can be seen observed in the results that at $548 \mathrm{~K}$ only $11.5 \%$ FAEE yield was obtained in the tubular reactor (TR), while $35 \%$ is reached using packed-bed tubular reactor (PBTR). At $573 \mathrm{~K}$ this yield is increased from $16 \%$ to $55 \%$ from the use TR to the PBTR at the same residence time. Such results demonstrate that much higher ethyl esters yields can be achieved at lower temperatures, small reaction times, also minimizing the total decomposition of fatty acids with the use of packed-bed tubular reactor. The increased performance of the reaction in the PBTR may be possibly due to the maximized interfacial surface area between the two flowing phases.

Silva et al. [79] proposed the use of microtube reactor for continuous synthesis of FAEE and reported yields of about $53 \%$ at $598 \mathrm{~K}, 20 \mathrm{MPa}$, oil to ethanol molar ratio of 1:20 and residence time of $25 \mathrm{~min}$. At similar conditions with addition of carbon dioxide as co-solvent 
$\left(\mathrm{CO}_{2}\right.$ to substrate mass ratio of $\left.0.2: 1\right)$ in the microtube reactor, Trentin et al. [74] reported $58 \%$ of FAEE yield. At this same condition, the reaction conducted in the work of Andrade et al. (2012) in the PBTR, resulted in FAEE yields about $60 \%$.

With the use of PBTR it can be obtained yields as high as 83\% at $598 \mathrm{~K}, 20 \mathrm{MPa}$, oil to ethanol molar ratio of 1:40 and 42 minutes of residence time. In such condition, it was observed $6.0 \mathrm{wt} \%$ of decomposition. In the evaluation of the effect of water content on the conversion, the authors reported $90 \%$ yield of ethyl esters and $<5.0 \mathrm{wt} \%$ of decomposition at similar conditions with addition of $10 \mathrm{wt} \%$ of water to the reaction medium.

\section{Conclusion}

The non-catalytic transesterification at supercritical conditions is a promising method for esters production and has strong advantages, such as fast reaction time, feedstock flexibility, production efficiency and environmentally friendly benefits, but as observed in this manuscript the application of this methodology has some limitations, such as the operation conditions of elevated temperature and pressure and the use of higher amounts of alcohol in the reaction medium, which results in high energy costs for the process and degradation of the products generated. The analysis of these facts generate critical of the use of supercritical technology in transesterification reactions making them an open problem. Furthermore, prospective research is reducing the operating parameters and the decomposition of the reaction components are required to industrial scale application of the supercritical method. Acknowledgements

The authors thank CNPq, PROCAD/Pro-Engenharia - CAPES, BIOEN FAPESP, Fundação Araucária and Maringa State University (UEM).

\section{Author details}

Camila da Silva ${ }^{1}$, Ignácio Vieitez ${ }^{2}$, Ivan Jachmanián², Fernanda de Castilhos ${ }^{3}$, Lúcio Cardozo Filho ${ }^{1}$ and José Vladimir de Oliveira ${ }^{4}$

1 Program of Post-Graduation in Chemical Engineering, State University of Maringa, Maringá, Brazil

2 Departamento de Ciencia y Tecnología de los Alimentos, Facultad de Química, UDELAR, Montevideo, Uruguay

3 Department of Chemical Engineering, Paraná Federal University, Curitiba, Brazi

4 Department of Chemical and Food Engineering, Federal University of Santa Catarina, Florianópolis, Brazil 


\section{References}

[1] Ma F, Hanna M. Biodiesel production: a review. Bioresource Technology 1999; 70(1), $1-15$.

[2] Srivastava A, Prasad R. Triglycerides-based diesel fuels. Renewable and Sustainable Energy Reviews 2000; 4(2), 111-133.

[3] Fukuda H, Kondo A, Noda H. Biodiesel Fuel Production by Transesterification of Oils. Journal of Bioscience and Bioengineering 2001; 92(5), 405-416.

[4] Meher LC, Vidya SD, Naik SN. Technical aspects of biodiesel production by transesterification: a review. Renewable and Sustainable Energy Reviews 2006; 10(3), 248268.

[5] Altin R, Çetinkaya S, Yucesu H S. The potential of using vegetable oil fuels as fuel for diesel engines. Energy Conversion and Management 2001; 42(5), 529-538.

[6] McCormick RL, Graboski MS, Alleman TL, Herring AM. Impact of biodiesel source material and chemical structure on emissions of criteria pollutants from a heavy-duty engine. Environmental Science \& Technology 2001; 35(9), 1742-1747.

[7] Vieitez I, Silva C, Alkimim I, Borges GR, Corazza FC, Oliveira JV, Grompone MA, Jachmanián I. Effect of temperature on the continuous synthesis of soybean esters under supercritical ethanol. Energy \& Fuels 2009; 23(1), 558-563.

[8] Achten WMJ, Verchot L, Franken YJ, Mathijs E, Singhe VP, Aertsa R, Muysa B. Jatropha bio-diesel production and use. Biomass and Bioenergy 2008; 32(12), 1063-1084.

[9] Berchmans HJ, Hirata S. Biodiesel production from crude Jatropha curcas L. seed oil with a high content of free fatty acids. Bioresource Technology 2008; 99(6), 17161721.

[10] Akgun, N., Iyscan E. Effects of process variables for biodiesel production by transesterification. European Journal of Lipid Science and Technology 2007; 109(5), 486-492.

[11] Robles-Medina A, González-Moreno PA, Esteban-Cerdán L, Molina-Grima E. Biocatalysis: towards ever greener biodiesel production. Biotechnology Advances 2009; 27(4), 398-408.

[12] Knothe G, Gerpen JV, Krahl J. The Biodiesel Handbook. AOCS Press: Champaign, USA; 2005.

[13] Pinto AC, Guarieiro LLN, RezendeMJC, Ribeiro NM, Torres EA, Lopes WA, Pereira PA P, Andrade JB. Biodiesel: An overview. Journal of Brazilian Chemical Society 2005; 16(6), 1313-1330.

[14] Marchetti JM, Errazu AF. Technoeconomic study of supercritical biodiesel production plant. Energy Conversion and Management 2008; 49(8), 2160-2164. 
[15] Freedman B, Butterfield RO, Pryde EH. Transesterification kinetics of soybean oil. Journal of the American Oil Chemists' Society 1986; 63(10), 1375-1380.

[16] Noureddini H, Zhu D. Kinetics of transesterification of soybean oil. Journal of the American Oil Chemists' Society 1997; 74(11), 1457-1461.

[17] Darnoko D, Cheryan M. Kinetics of palm oil: Transesterification in a batch reactor. Journal of the American Oil Chemists' Society 2000; 77(12), 1263-1266.

[18] Ferrari RA, Silva V, Oliveira EAS. Biodiesel de soja: Taxa de conversão em ésteres etílicos, caracterização físicoquímica e consumo em gerador de energia. Química Nova 2005; 28(1), 19-23.

[19] Martinez M, Vicente G, Aracil J, Esteban A. Kinetics of sunflower oil methanolysis. Industrial \& Engineering Chemistry Research 2005; 44(15), 5447-5454.

[20] Martinez M, Vicente G, Aracil J. Kinetics of Brassica carinata oil methanolysis. Energy \& Fuels 2006; 20(4), 1722-1726.

[21] Oliveira D, Di Luccio M, Faccio C, Rosa CD, Bender JP, Lipke N, Amroginski C, Dariva C, Oliveira JV. Optimization of alkaline transesterificação of soybean oil and castor oil for biodiesel production. Applied Biochemistry and Biotechnology 2005; 121(1), 553-559.

[22] Meneghetti SMP, Meneghetti MR, Wolf CR, Silva EC, Lima GES, Silva LL, Serra TM, Cauduro F, Oliveira LG. Biodiesel from castor oil: A comparison of ethanolysis versus methanolysis. Energy \& Fuels 2006; 20(5), 2262-2265.

[23] Lima JRO, Silva RB, Silva CCM, Santos LSS, Santos JR, Moura EM, Moura CVR. Biodiesel de babaçu (Orbignya sp.) obtido por via etanólica. Química Nova 2007; 30(3), 600-603.

[24] Kusdiana D, Saka S. Biodiesel fuel from rapeseed oil as prepared in supercritical methanol. Fuel 2001; 80(2), 225-231.

[25] Zhang Y, Dubé M A, Mclean D D, Kates M. Biodiesel production from waste cooking oil. Bioresource Technology 2003; 89(1), 1-16.

[26] Vyas AP, Verma JL, Subrahmanyam N. A review on FAME production processes. Energy \& Fuel 2010; 89(1), 1-9.

[27] Pinnarat T, Savage P. Assessment of non-catalytic biodiesel synthesis using supercritical reaction conditions. Industrial \& Engineering Chemistry Research 2008; 47(18), 6801-6808.

[28] Berrios M, Martin MA, Chica AF, Martin A. Study of esterification and transesterification in biodiesel production from used frying oils in a closed system. Chemical Engineering Journal 2010; 160(2), 473-479. 
[29] Srilatha K, Issariyakul T, Lingaiah N, Sai Prasad PS, Kozinski J, Dalai AK. Efficient Esterification and Transesterification of Used Cooking Oil Using 12-Tungstophosphoric Acid (TPA)/ $\mathrm{Nb}_{2} \mathrm{O}_{5}$ Catalyst. Energy \& Fuels 2010; 24(9), 4748-4755.

[30] Thanh LT, Okitsu K, Sadanaga Y, Takenaka N, Maeda Y, Bandow H. A two-step continuous ultrasound assisted production of biodiesel fuel from waste cooking oils: A practical and economical approach to produce high quality biodiesel fuel. Bioresource Technology 2010; 101(14), 5394-5401.

[31] Corro G, Tellez N, Jimenez T, Tapia A, Banuelos F, Vazquez-Cuchillo O. Biodiesel from waste frying oil. Two step process using acidified $\mathrm{SiO}_{2}$ for esterification step. Catalysis Today 2011; 166(1), 116-122.

[32] Gan S, Ng HK, Ooi CW, Motala NO, Anas M, Ismail F. Ferric sulphate catalysed esterification of free fatty acids in waste cooking oil. Bioresource Technology 2010; 101(19), 7338-7343.

[33] Rocha LLL, Ramos ALD, Filho NRA, Furtado NC, Taft CA, Aranda D. Production of biodiesel by a two-step niobium oxide catalyzed hydrolysis and esterification. Letters in Organic Chemistry 2010; 7(8), 571-578.

[34] Sousa JS, Oliveira EAC, Freire DMG, Aranda D. Application of lipase from the physic nut (Jatropha curcas L.) to a new hybrid (enzyme/chemical) hydroesterification process for biodiesel production. Journal of Molecular Catalysis B, Enzymatic 2010; 65(1), 133-137.

[35] Antunes WM, Veloso CO, Henriques CA. Transesterification of soybean oil with methanol catalyzed by basic solids. Catalysis Today 2008; 133(1), 548-554.

[36] Park Y, Lee D, Kim D, Lee J, Lee K. The heterogeneous catalyst system for the continuous conversion of free fatty acids in used vegetable oils for the production of biodiesel. Catalysis Today 2008; 131(1), 238-243.

[37] Trakarnpruk W, Porntangjitlikit S. Palm oil biodiesel synthesized with potassium loaded calcined hydrotalcite and effect of biodiesel blend on elastomers properties. Renewable Energy 2008; 33(7), 1558-1563.

[38] Oliveira D, Oliveira JV. Kinetics of the enzymatic alcoholysis of palm kernel oil in supercritical $\mathrm{CO}_{2}$. Industrial \& Engineering Chemistry Research 2000; 39(12), 4450.

[39] Oliveira D, Oliveira JV. Enzymatic alcoholysis of palm kernel oil in n-hexane and $\mathrm{SCCO}_{2}$. The Journal of Supercritical Fluids 2001; 19(2), 141-148.

[40] Dalla Rosa C, Morandim MB, Ninow JL, Oliveira D, Treichel H, Oliveira JV. Lipasecatalyzed production of fatty acid ethyl esters from soybean oil in compressed propane. The Journal of Supercritical Fluids 2008; 47(1), 49-53.

[41] Dalla Rosa C, Morandim MB, Ninow JL, Oliveira D, Treichel H, Oliveira JV. Continuous lipase-catalyzed production of fatty acid ethyl esters from soybean oil in compressed fluids. Bioresource Technology 2009; 100(23), 5818-5826. 
[42] Leadbeater NE, Stencel LM. Fast, Easy Preparation of biodiesel using microwave heating. Energy \& Fuels 2006; 20(5), 2281-2283.

[43] Barnard TM, Leadbeater NE, Boucher MB, Stencel LM, Wilhite BA. Continuous-flow preparation of biodiesel using microwave heating. Energy \& Fuels 2007; 21(3), 17771781.

[44] Melo CAR, Albuquerque CER, Fortuny M, Dariva C, Egues S, Santos AF, Ramos ALD. Use of microwave irradiation in the non-catalytic esterification of C18 fatty acids. Energy \& Fuels 2009; 23(1), 580-585.

[45] Teixeira LSG, Assis JCR, Mendonça DR, Santos ITV, Guimarães, PRB, Pontes LAM, Teixeira JSR. Comparison between conventional and ultrasonic preparation of beef tallow biodiesel. Fuel Processing Technology 2009; 90(9), 1164-1166.

[46] Yu D, Tian L, Wu H, Wang S, Wang Y, Ma D, Fang X. Ultrasonic irradiation with vibration for biodiesel production from soybean oil by Novozym 435. Process Biochemistry 2010; 45(4), 519-525.

[47] Badday AS, Abdullah AZ, Lee KT, Khayoon MS. Intensification of biodiesel production via ultrasonic-assisted process: A critical review on fundamentals and recent development. Renewable and Sustainable Energy Reviews 2012; 16(7), 4574-4587

[48] Kusdiana D, Saka S. Kinetics of transesterification in rapeseed oil to Biodiesel fuel as treated in supercritical methanol. Fuel 2001; 80(5), 693-698.

[49] Kusdiana D, Saka S. Methyl esterification of free fatty acids of rapeseed oil as treated in supercritical methanol. Journal of chemical Engineering of Japan 2001; 34(3), 383-387.

[50] Demirbas A. Biodiesel from vegetable oils via transesterification in supercritical methanol. Energy: Conversion \& Management 2002; 43(17), 2349-2356.

[51] Madras G, Kolluru C, Kumar R. Synthesis of biodiesel in supercritical fluids. Fuel 2004; 83(14), 2029-2033.

[52] Warabi Y, Kusdiana D, Saka S. Reactivity of triglycerides and fatty acids of rapeseed oil in supercritical alcohols. Bioresource Technology 2004; 91(3), 283-287.

[53] Demirbas A. Biodiesel production via non-catalytic SCF method and Biodiesel fuel characteristics. Energy Conversion \& Management 2006; 47(15), 2271-2282.

[54] Kusdiana D, Saka S. Effetcs of water on biodiesel fuel production by supercritical methanol treatment. Bioresource Techonology 2004; 91(3), 289-295.

[55] Wang C, Zhou J, Chen W, Wang W, Wu Y, Zhang J, Chi R, Ying W. Effect of weak acids as a catalyst on the transesterification of soybean oil in supercritical methanol. Energy \& Fuels 2008; 22(5), 3479-3483.

[56] Imahara H, Minami E, Hari S, Saka S. Thermal stability of biodiesel in supercritical methanol. Fuel 2007; 87(1), 1-6. 
[57] Vieitez I, Silva C, Borges GR, Corazza FC, Oliveira JV, Grompone MA, Jachmanián I. Continuous production of soybean biodiesel in supercritical ethanol-water mixtures. Energy \& Fuels 2008; 22(4), 2805-2809.

[58] Vieitez I, Pardo MJ, Silva C, Bertoldi C, Castilhos F, Oliveira JV, Grompone MA, Jachmanián I. Continuous synthesis of castor oil ethyl esters under supercritical ethanol. The Journal of Supercritical Fluids 2011; 56(3), 271-276.

[59] Olivares-Carrillo P, Quesada-Medina J. Synthesis of biodiesel from soybean oil using supercritical ethanol in a one-step catalyst-free process in batch reactor. The Journal of Supercritical Fluids 2011; 58(16), 378-384.

[60] Shin H, Lim S, Bae S, Oh C. Thermal decomposition and stability of fatty acid methyl esters in supercritical methanol. Journal of Analytical and Applied Pyrolysis 2011; 92(2), 332-338.

[61] Anitescu G, Deshpande A, Tavlarides LL. Integrated technology for supercritical biodiesel production and power cogeneration. Energy \& Fuel 2008; 22(2), 1391-1399.

[62] Aimaretti N, Manuale DI, Mazzieri VM, Vera CR, Yori C. Batch study of glycerol decomposition in one-stage supercritical production of biodiesel. Energy \& Fuel 2009; 23(2), 1076-1080.

[63] Kasim NS, Tsai T, Gunawan S, Ju Y. Biodiesel production from rice bran oil and supercritical methanol. Bioresource Technology 2009; 100(8), 2399-2403.

[64] Marulanda VF, Anitescu G, Tavlarides LL. Investigations on supercritical transesterification of chicken fat for biodiesel production from low cost lipid feedstocks. The Journal of Supercritical Fluids 2010; 54(1), 53-60.

[65] Kusdiana D, Saka S. Two-Step preparation for catalyst-free biodiesel fuel production. Applied Biochemistry and Biotechonology 2004; 113(1), 781-791.

[66] Minami E, Saka S. Kinetics of hydrolysis and methyl esterification for biodiesel production in two-step supercritical methanol process. Fuel 2006; 85(17), 2479-2483.

[67] He H, Tao W, Zhu S. Continuous production of biodiesel from vegetable oil using supercritical methanol process. Fuel 2007; 86(3), 442-447.

[68] Silva C, Weschenfelder TA, Rovani S, Corazza FC, Corazza ML, Dariva C, Oliveira JV. Continuous production of fatty ethyl esters from soybean oil in compressed ethanol. Industrial \& Engineering Chemistry Research 2007; 46(16), 5304-5309.

[69] Cao W, Han H, Zhang J. Preparation of biodiesel from soybean oil using supercritical methanol and $\mathrm{CO}_{2}$ as co-solvent. Process Biochemistry 2005; 40(9), 3148-3156.

[70] Han H, Cao W, Zhang J. Preparation of biodiesel from soybean oil using supercritical methanol and co-solvent. Fuel 2005; 84(4), 347-351. 
[71] Hegel P, Mabe G, Pereda S, Brignole EA. Phase transitions in a biodiesel reactor using supercritical methanol. Industrial \& Engineering Chemistry Research 2007; 46(19), 6360-6365.

[72] Yin J, Z, Xiao M, Song JB. Biodiesel from soybean oil in supercritical methanol with co-solvent. Energy Conversion and Management 2007; 49(5), 908-912.

[73] Bertoldi C, Silva C, Bernardon JP, Corazza ML, Cardozo Filho L, Oliveira JV, Corazza FC. Continuous production of biodiesel from soybean oil in supercritical ethanol and carbon dioxide as co-solvent. Energy \& Fuels 2009; 23(10), 5165-5172.

[74] Trentin CM, Lima AP, Alkimim IP, Silva C, Castilhos F, Mazutti MA, Oliveira JV. Continuous production of soybean biodiesel with compressed ethanol in a microtube reactor using carbon dioxide as co-solvent. Fuel Processing Technology 2011; 92(5), 952-958.

[75] D’ Ippolito SA, Yori JC, Iturria ME, Pieck CL, Vera CR. Analysis of a two-step, noncatalytic, supercritical biodiesel production process with heat recovery. Energy \& Fuels 2007; 21(1), 339-346.

[76] Silva C, Lima AP, Castilhos F, Cardozo Filho L, Oliveira JV. Non-catalytic production of fatty acid ethyl esters from soybean oil with supercritical ethanol in a two-step process using a microtube reactor. Biomass \& Bioenergy 2011; 35(1), 526-532.

[77] Silva C, Borges G, Castilhos F, Oliveira JV, Cardozo Filho L. Continuous production of fatty acid ethyl esters from soybean oil at supercritical conditions. Acta Scientiarum. Technology 2012; 34(2), 185-192.

[78] Chen $\mathrm{CH}$, Chen WH, Chang CMJ, Lai SM, Tu CH. Biodiesel production from supercritical carbon dioxide extracted Jatropha oil using subcritical hydrolysis and supercritical methylation. The Journal of Supercritical Fluids 2010; 52(2), 228-234.

[79] Silva C, Castilhos F, Oliveira JV, Cardozo Filho L. Continuous production of soybean biodiesel with compressed ethanol in a microtube reactor. Fuel Processing Technology 2010; 91(10), 1274-1281.

[80] Andrade SB, Abdala ACA, Silva EA, Cabral VF, Oliveira JV, Cardozo Filho L, Silva C. Non-catalytic production of ethyl esters from soybean oil in a continuous packed bed reactor (Submitted to Fuel Processing Technology).

[81] Glisic S, Skala D. The problems in design and detailed analyses of energy consumption for biodiesel synthesis at supercritical conditions. The Journal of Supercritical Fluids 2009; 49(2), 293-301.

[82] Deshpande A, Anitescu G, Rice PA, Tavlarides LL. Supercritical biodiesel production and power cogeneration: Technical and economic feasibilities. Bioresource Technology 2010; 101(6), 1834-1843. 
[83] Johnson DT, Taconi KA. The glycerin glut: Options for the value-added conversion of crude glycerol resulting from biodiesel production. Environmental Progress 2007; 26(4), 338-348.

[84] Zhou C, Beltramini JN, Fan Y, Lu GQ. Chemoselective catalytic conversion of glycer$\mathrm{ol}$ as a biorenewable source to valuable commodity chemicals. Chemical Society Reviews 2008; 37(1), 527-549.

[85] Marchetti JM, Errazu AF. Possible methods for biodiesel production. Renewable \& Sustainable Energy Reviews 2007; 11(6), 1300-1311.

[86] Sasaki T, Omoyubi S, Fumio O. Method for preparing fatty acid esters and fuel comprising fatty acid esters. United States Patent: 2001; 6,187,939.

[87] Crawford JW, Crawford JM, Crafts R. Transesterification of oil to form biodiesels United States Patent: 2007; 059512.

[88] Kiwjaroun C, Tubtimdee C, Piumsomboon P. LCA studies comparing biodiesel synthesized by conventional and supercritical methanol methods. Journal of Cleaner Production 2009; 17(2), 143-153.

[89] Marulanda VF. Biodiesel production by supercritical methanol transesterification: process simulation and potential environmental impact assessment. Journal of Cleaner Production 2012; 33(1), 109-116.

[90] Lee S, Posarac D, Ellis N. An experimental investigation of biodiesel synthesis from waste canola oil using supercritical methanol. Fuel 2012; 91(1), 229-237.

[91] Official Methods and Recommended Practices of the American Oil Chemists' Society (Method AOCS Ce 2-66), 4th ed., edited by R.E. Walker, American Oil Chemists' Society, Champaign; 1990.

[92] Ginosar D, Fox R, Petkovic L M, Christian S. Production of biodiesel using expanded gas solvents. United States Patent: 2006; 121584.

[93] Imahara $\mathrm{H}$, Xin J, Saka S. Effect of $\mathrm{CO}_{2} / \mathrm{N}_{2}$ addition to supercritical methanol on reactivities and fuel qualities in biodiesel production. Fuel 2009; 88(7), 1329-1332.

[94] Tan KT, Lee KT, Mohamed AR. Effects of free fatty acids, water content and co-solvent on biodiesel production by supercritical methanol reaction. The Journal of Supercritical Fluids 2010; 53(1), 88-91.

[95] Muppaneni T, Reddy HK, Patil PD, Dailey P, Aday C, Deng S. Ethanolysis of camelina oil under supercritical condition with hexane as a co-solvent. Applied Energy 2012; 94(1), 84-88.

[96] Temelli F, King JW, List GR. Conversion of oils to monoglycerides by glycerolysis in supercritical carbon dioxide media. Journal of the American Oil Chemists' Society 1996; 73(6), 699-706. 
[97] Ndiaye PM, Franceschi E, Oliveira D, Dariva C, Tavares FW, Oliveira JV. Phase behavior of soybean oil, castor oil and their fatty acid ethyl esters in carbon dioxide at high pressures. The Journal of Supercritical Fluids 2006; 37(1), 29-37.

[98] Lanza M, Priamo WL, Oliveira JV, Dariva C, Oliveira D. The effect of temperature, pressure, exposure time, and depressurization rate on lipase activity in $\mathrm{SCCO}_{2}$. Applied Biochemistry and Biotechnology 2004; 113(1), 181-187.

[99] Pereda S, Bottini SB, Brignole EA. Gas-liquid reactions under supercritical conditions - Phase equilibria and thermodynamic modeling. Fluid Phase Equilibria 2002; 194(30), 493-499.

[100] Busto M, D' Ippolito SA, Yori JC, Iturria ME, Pieck CL, Grau JM, Vera CR. Influence of the axial dispersion on the performance of tubular reactors during the noncatalytic supercritical transesterification of triglycerides. Energy \& Fuels 2006; 20(6), 2642-2647.

[101] Qiu Z, Zhao L, Weatherley L. Process intensification technologies in continuous biodiesel production. Chemical Engineering and Processing 2010; 49(4), 323-330.

[102] Dewitt S H. Microreactors for chemical synthesis. Current Opinion in Chemical Biology 1999; 3(1), 350-356.

[103] Worz O, Jackel K P, Richter T, Wolf A. Microreactors, a new efficient tool for optimum reactor design. Chemical Engineering Science 2001; 56(3), 1029-1033.

[104] Fletcher PDI, Haswell SJ, Villar E, Warrington BH, Watts P, Wong SYF, Zhang X. Micro reactors: principles and applications in organic synthesis. Tetrahedron 2002; 58(24), 4735-4757.

[105] Hessel V, Hardt S, Lowe H. Chemical micro process engineering: Fundamentals, modelling and reactions. Editora Wiley-VCH Verlag: Germany; 2005.

[106] Ataya F, Dube MA, Ternan M. Transesterification of canola oil to fatty acid methyl ester (FAME) in a continuous flow liquid-liquid packed bed reactor. Energy \& Fuels 2008; 22(5), 3551-3556.

[107] Yu X, Wen Z, Lin Y, Tu S, Wang Z, Yan J. Intensification of biodiesel synthesis using metal foam reactors. Fuel 2010; 89(11), 3450-3456.

[108] Santacesaria E, Di Serio M, Tesser R, Tortorelli M, Turco R, Russo V. A simple device to test biodiesel process intensification. Chemical Engineering and Processing 2011; 50(10), 1085-1094.

[109] Sun J, Ju J, Zhang L, Xu N. Synthesis of biodiesel in capillary microreactors. Industrial \& Engineering Chemistry Research 2008; 47(5), 1398-1403.

[110] Pohar A, Plazl I. Laminar to Turbulent Transition and Heat Transfer in a Microreactor: Mathematical Modeling and Experiments. Industrial \& Engineering Chemistry Research 2008; 47(19); 7447-7455. 
[111] Ehrfeld W, Lowe H, Hessel V. Microreactors: New Technology for Modern Chemistry; Wiley-VCH: New York; 2000.

[112] Guan G, Kusakabe K, Moriyama K, Sakurai N. Transesterification of sunflower oil with methanol in a microtube reactor. Industrial \& Engineering Chemistry Research 2009; 48(3), 1357-1363.

[113] Zhang X, Stefanick S, Villani F J. Application of microreactor technology in process development. Organic Process Research \& Developmente 2004; 8(3), 455-460.

[114] Achenbach E. Heat and flow characteristics of packed beds. Experimental Thermal and Fluid Science 1994; 10(1), 17-27.

[115] Su Y. The Intensification of Rapid Reactions for Multiphase Systems in a Microchannel Reactor by Packing Microparticles. AIChE Journal 2011; 57(6), 1409-1418.

[116] European normative EN 14103, Determination of ester and linolenic acid methyl ester contents, issued by Asociación Española de Normalización y Certificación, Madrid; 2003.

[117] Vieitez I, Silva C, Alkimim I, Borges GR, Corazza FC, Oliveira JV, Grompone MA, Jachmanián I. Continuous catalyst-free methanolysis and ethanolysis of soybean oil under supercritical alcohol/water mixtures. Renewable Energy 2010; 35(9), 19761981.

[118] Vieitez I, Silva C, Alkimim I, Castilhos F, Oliveira J V, Grompone M A, Jachmanián I. Stability of ethyl esters from soybean oil exposed to high temperatures in supercritical ethanol. The Journal of Supercritical Fluids 2011; 56(3), 265-270.

[119] Vieitez I, Irigaray B, Casullo P, Pardo M, Grompone MA, Jachmanián I. Effect of free fatty acids on the efficiency of the supercritical ethanolysis of vegetable oils from different origins. Energy \& Fuels 2012; 26(3), 1946-1951.

[120] Vieitez I, Silva C, Castilhos F, Oliveira JV, Grompone MA, Jachmanián I. Elaboración de biodiesel mediante la transesterificación sin catalizador de aceites en alcoholes supercríticos. Ingeniería Química 2011; 40(1), 10-19.

[121] Kulkarni MG, Dalai AK. Waste cooking oil an economical source for biodiesel: A review. Industrial \& Engineering Chemistry Research 2006; 45(9), 2901-2913.

[122] Lam MK, Lee KT, Mohamed AR. Homogeneous, heterogeneous and enzymatic catalysis for transesterification of high free fatty acid oil (waste cooking oil) to biodiesel: A review. Biotechnology Advances 2010; 28(4), 500-518.

[123] Lin L, Cunshan Z, Vittayapadung S, Xiangqian S, Mingdong D. Opportunities and challenges for biodiesel fuel. Applied Energy 2011; 88(4), 1020-1031.

[124] Agência Nacional do Petróleo, Gás Natural e Biocombustíveis. Boletim mensal de biodiesel. Brasília, Brazil, Agência Nacional de Petróleo, Gás Natural e Biocombustíveis, January; 2012. 9p. Retrieved from http://www.anp.gov.br. 
[125] Official Methods and Recommended Practices of the American Oil Chemists' Society (Method AOCS 1c-85), 4th ed., edited by R.E. Walker, American Oil Chemists' Society, Champaign; 1990.

[126] Ngamprasertsith S, Sawangkeaw R. Transesterification in Supercritical Conditions. In: Biodiesel - Feedstocks and Processing Technologies. Rijeka: InTech; 2011. p247-268.

[127] Day CY, Chang CJ, Chen CY. Phase equilibrium of ethanol $+\mathrm{CO}_{2}$ and acetone $+\mathrm{CO}_{2}$ at elevated pressure. Journal of Chemical \& Engineering Data 1996; 41(4), 839-843.

[128] Pohler H, Kiran E. Volumetric properties of carbon dioxide + ethanol at high pressures. Journal of Chemical \& Engineering Data 1997; 42(2), 384-388.

[129] Joung SN, Yoo CW, Shin HY, Kim SY, Yoo KP, Lee CS, Huh WS. Measurements and correlation of high-pressure VLE of binary $\mathrm{CO}_{2}$-alcohol systems (methanol, ethanol, 2-methoxyethanol and 2-ethoxyethanol). Fluid Phase Equilibria 2001; 185(1), 219-230.

[130] Granado ML, Alonso DM, Alba-Rubio AC, Mariscal R, Ojeda M, Brettes P. Transesterification of triglycerides by $\mathrm{CaO}$ : Increase of the reaction rate by biodiesel addition. Energy \& Fuels 2009; 23(4), 2259-2263. 